\title{
R-848 triggers the expression of TLR7/8 and suppresses HIV replication in monocytes
}

\author{
Hua Niann', Wen-Qing Geng ${ }^{1}$, Hua-Lu Cui ${ }^{1}$, Ming-jia Bao ${ }^{2}$, Zi-ning Zhang ${ }^{1}$, Min Zhang ${ }^{1}$, Ying Pan ${ }^{1}$, Qing-Hai Hu ${ }^{1}$ \\ and Hong Shang ${ }^{1 *}$
}

\begin{abstract}
Background: Toll-like receptors (TLR) 7 and 8 are important in single-stranded viral RNA recognition and may play a role in HIV infection and disease progression. We analyzed TLR7/8 expression and signaling in monocytes from HIV-infected and uninfected subjects to investigate a pathway with new potential for the suppression of HIV replication.
\end{abstract}

Methods: Eighty-one HIV-infected and uninfected subjects from Liaoning and Henan provinces in China participated in this study. Monocytes were isolated from subjects' peripheral blood mononuclear cells by magnetic bead selection. TLR7 and TLR8 mRNA was measured using quantitative real-time reverse transcriptase PCR. R-848 (resiquimod) was used as a ligand for TLR7 and TLR8 in order to 1) assess TLR7/8-mediated monocyte responsiveness as indicated by IL-12 p40 and TNF- $\alpha$ secretion and 2) to examine HIV replication in cultured monocytes in the presence of R-848.

Results: We found that expression of TLR7/8 mRNA in peripheral blood monocytes decreased with disease progression. TLR7 expression was decreased with stimulation with the TLR7/8 agonist, R-848, in vitro, whereas TLR8 expression was unaffected. Following R-848 stimulation, monocytes from HIV-infected subjects produced significantly less TNF- $\alpha$ than those from uninfected subjects, but trended towards greater production of IL-12 than stimulated monocytes from uninfected subjects. R-848 stimulation also suppressed HIV replication in cultured monocytes.

Conclusions: Our study provides evidence that the TLR7 and TLR8 triggering can suppress HIV replication in monocytes and lead to postpone HIV disease progression, thereby offering novel targets for immunomodulatory therapy.

Keywords: Toll-like receptor, HIV, Monocytes, R-848

\section{Background}

Infection with HIV-1, the causative agent of AIDS, is characterized clinically by a long asymptomatic period of latency preceding the development of AIDS. Even during this period of clinical latency, the virus replicates continuously and causes new rounds of infection. In recent years, many researchers have focused on adaptive immune responses against HIV infection. To date, the mechanisms that modulate HIV replication during this

\footnotetext{
* Correspondence: hongshang100@hotmail.com

${ }^{1}$ Key Laboratory of AIDS Immunology of Ministry of Health, Department of Laboratory Medicine, No.1 Hospital of China Medical University, No.155

Nanjing North Street, Heping District, Shenyang 110001, China
}

Full list of author information is available at the end of the article clinically latent stage are not completely clear and studies of HIV immunotherapy and vaccination have not shown great progress.

The importance of innate immunity in HIV infection is becoming increasingly apparent [1-3]. Innate immunity serves as the first line of defense against microbial pathogens and is also responsible for the initiation of inflammatory responses through the release of a variety of cytokines, chemokines, and antimicrobial factors. Monocytes, the precursors of macrophages and dendritic cells, are involved in the innate immune response via cognate interactions and production of proinflammatory cytokines, such as interferons (IFNs), IL-12, IL-6 and tumor necrosis factor alpha (TNF- $\alpha)$. In particular, toll-

\section{Biomed Central}


like receptors (TLRs) that are expressed on monocytes can signal cytokine release, cellular activation, and upregulation of the MHC Class I or Class II [4], and thus help link the innate and the adaptive immune responses.

TLRs are a family of pattern recognition receptors that mediate essential mechanisms of innate immunity against microbial pathogens [5-7]. TLRs are grouped by their preferences for conserved structural motifs of microorganisms. TLR3, 7, 8, and 9 are implicated in anti-viral defense $[5,8]$. A recent study reported that TLR7/8 can recognize uridine-rich ssRNA (ssRNA40) derived from the HIV-1 long terminal repeat (LTR) [9], suggesting that TLR7/8 may be involved in HIV infection as other investigators have previously reported $[10,11]$.

It is still unknown whether TLR7/8 expression in monocytes is related to disease progression in HIVinfected patients or whether it represents a protective factor in those patients who are slow disease-progressors. Both TLR7 and 8 recognize single-stranded viral RNA (ssRNA) [12,13], lead to NF $-\kappa$ B activation [14], and promote the production of cytokines such as IL-12 and TNF- $\alpha$ [15]. NF- $\kappa$ B is critical for the transcription of most immune response genes, inducing both types I and II cytokines [16]. Ironically, there are NF- $\kappa \mathrm{B}$ binding sites located within the HIV LTR [14] that can bind $\mathrm{NF}-\kappa \mathrm{B}$ and enhance HIV replication. Thus, the role of TLR7/8 signaling in monocytes' response to HIV replication merits further investigation.

In this study, we examined monocyte expression of TLR7 and 8 mRNA from subjects with HIV over the course of disease progression. We also assessed TLR7/8dependent cytokine secretion and HIV replication in monocytes stimulated with the synthetic TLR7/8 ligand $\mathrm{R}-848$. We demonstrate that HIV disease progression is influenced by TLR7/8 expression and signaling in monocytes, offering additional targets in the pursuit of treatments and cures for AIDS.

\section{Methods}

\section{Study subjects}

Sixty-three HIV-1-infected subjects from Liaoning and Henan provinces in China were enrolled in the study.
All had been previously diagnosed using an anti-HIV antibody screening test (Vironostika, Organon Tednika, The Netherlands) which was confirmed by immunoblotbased testing (Gene Lab Diagnostics, Singapore). HIVinfected subjects were classified into three clinical groups. Subjects in the first group were characterized as "slow progressors" (SPs), with persistent $\mathrm{CD}^{+}{ }^{+}$cell counts greater than 500 cells/ $\mu \mathrm{l}$, no anti-retroviral therapy, and no clinical signs of disease for at least 10 years. Subjects in the second group were characterized as "chronic HIV infection subjects", who had CD4 ${ }^{+}$cell counts between 200 and 500 cells/ $\mu$ l with no antiretroviral therapy and no AIDS-defining symptoms. Patients in the third group were labeled "AIDS subjects", consisting of patients with $<200 \mathrm{CD}^{+}$cells/ $\mu \mathrm{l}$ and/or the appearance of opportunistic infections or AIDS-defining symptoms according to the World Health Organization classification. According to these criteria, the study included 20 SPs, 25 chronic HIV infection subjects, 18 AIDS subjects and $18 \mathrm{HIV}$-negative healthy persons (Table 1). All control subjects had normal blood cell counts, normal levels of hemoglobin, and normal liver function and did not have any history of immune system disease. Blood samples from subjects were obtained when opportunistic infection was not present. Samples from HIV-infected and control subjects were always handled in parallel. All subjects included here gave informed consent and written approval was obtained from the appropriate hospital ethics committees. All investigations were conducted according to Helsinki Declaration guidelines.

\section{Isolation, culture, and stimulation of monocytes}

Peripheral blood mononuclear cells (PBMCs) were isolated from buffy coats of heparinized blood by FicollHypaque (Amersham Biosciences) density gradient centrifugation; monocytes were further isolated using CD14 ${ }^{+}$-conjugated magnetic beads (Miltenyi Biotech, Germany) for the positive selection according to the manufacturer's instructions. The purity of the monocyte population was $>97 \%$ as determined by flow cytometry with phycoerythrin (PE)-conjugated anti-CD14 antibody

Table 1 Details of study subjects in each group

\begin{tabular}{|c|c|c|c|c|c|c|}
\hline $\begin{array}{l}\text { Study } \\
\text { group }\end{array}$ & $\begin{array}{l}\text { Females/Males } \\
\text { (age) }^{a}\end{array}$ & $\begin{array}{l}\text { CD4 Count (cells/ } \\
\mu \mathrm{l})^{\mathrm{b}}\end{array}$ & $\begin{array}{l}\text { Plasma Viral Load (copies/ } \\
\mathrm{ml})^{\mathbf{b}}\end{array}$ & $\begin{array}{l}\text { HCV Positive } \\
n^{c}\end{array}$ & $\begin{array}{l}\text { HBV Positive } \\
\mathrm{n}^{\mathrm{c}}\end{array}$ & $\begin{array}{l}\text { Receiving HAART } \\
\text { therapy } \mathrm{n}^{\mathrm{c}}\end{array}$ \\
\hline SPs $(20)$ & 8/12 (47: 33-56) & $637(563-722)$ & $47500(24500-407750$ & 5 & 0 & 0 \\
\hline $\begin{array}{l}\text { HIV chronic } \\
(25)\end{array}$ & 11/14 (44: 30-54) & $411(328-487)$ & 11000 (2005-75000) & 5 & 1 & 0 \\
\hline $\operatorname{AIDS}(18)$ & 7/11 (48: 37-59) & $107(55-151)$ & $4100(790-16000)$ & 4 & 1 & 4 \\
\hline Control(18) & 9/9 (46: 36-54) & $823(524-1135)$ & $\mathrm{ND}^{\mathrm{d}}$ & 0 & 0 & $N D^{d}$ \\
\hline
\end{tabular}

\footnotetext{
, Numbers of Females/Numbers of Males (median age in years: age interquartile range)

b, Median (interquartile range)

c, n, Positive Numbers

${ }^{d}, \mathrm{ND}$, not data
} 
(BD Pharmingen). Cell viability of monocytes at isolation was $>90 \%$ as determined by trypan blue. Monocytes were cultured in RPMI-1640 supplemented with $10 \%$ fetal bovine serum, $2 \mathrm{mM}$ L-glutamine, $25 \mathrm{mM}$ HEPES, $100 \mathrm{IU} / \mathrm{ml}$ penicillin $\mathrm{G}$ and $100 \mu \mathrm{g} / \mathrm{ml}$ streptomycin, and were cultured at $5 \times 10^{5}$ cells $/ 0.5 \mathrm{ml} /$ well on 48-well flat bottom tissue culture plates following the protocol described by Bekeredjian-Ding et al. [15]. The antibiotics were added to prevent bacterial growth; cultures grown in media lacking antibiotics did not display different TLR7/8 expression. Monocytes were stimulated with the TLR7/8 agonist R-848 (resiquimod, Alexis) at $2.5 \mu \mathrm{g} / \mathrm{ml}$ [15] or medium alone (controls) in cultures at $37^{\circ} \mathrm{C}, 5 \% \mathrm{CO}_{2}$ for $24 \mathrm{~h}$, at which point monocyte cytokine secretion was fully functional and the levels of TLR 7/8 expression were also evaluated. Cell-free supernatants were harvested after a 24-h culturing period and the concentrations of IL-12p40 (the bioactive form of IL-12) and TNF- $\alpha$ were determined using an ELISA assay (R\&D and eBioscience, respectively). All supplemented media were found free of endotoxin (lack of TNF- $\alpha$ induction in monocytes) [17]. HIV RNA load in supernatant was also measured to assess viral replication before and after culture of monocytes from HIVinfected patients. Monocytes were washed three times after separation and before culture; HIV RNA was not detected in any initial monocyte culture. Monocytes were cultured in 48 well plates with approximately $5 \times$ $10^{5}$ cells $/ 0.5 \mathrm{ml} /$ well which was sufficient to produce enough virus in $48 \mathrm{~h}$ to exceed detection limits [18].

\section{HIV RNA load measurement}

HIV-1 RNA levels in culture supernatants were extracted from each sample with the Nuclisens extractor (bioMérieux) and quantified using the Nuclisens EasyQ (version 1.1) assay (bioMérieux) following the manufacturer's instructions.

\section{Determination of $\mathrm{CD}^{+}$cell counts}

$\mathrm{CD}^{+}$cell counts were measured using a FACS Calibur flow cytometer (Becton-Dickinson). A single-platform lyse/no-wash procedure was performed using Trucount tubes and TriTEST CD4-FITC/CD8-PE/CD3-PerCP reagents (BD Biosciences).

\section{Measurement of TLR7/8 mRNA expression}

Total RNA was extracted from monocytes using the RNeasy Protect Mini Kit (QIAGEN) according to the manufacturer's protocol. The concentration of total RNA extracted from monocytes was determined by measuring optical density at 260/280 nm. Reverse transcriptase polymerase chain reaction was carried out using a kit from the Takara according to the manufacturer's protocol. The RT reaction consisted of $500 \mathrm{ng}$ of total RNA, $0.5 \mu \mathrm{l}$ Oligo dT $(50 \mu \mathrm{mol}), 0.5 \mu \mathrm{l}$ random hexamers $(100 \mu \mathrm{mol}), 2 \mu \mathrm{l} 5 \times$ PrimeScript Buffer, adjusted to $10 \mu \mathrm{l}$ with Rnase-Free $\mathrm{dH}_{2} \mathrm{O}$. Reaction conditions were set at $37^{\circ} \mathrm{C}$ for $15 \mathrm{~min}, 85^{\circ} \mathrm{C}$ for $5 \mathrm{~s}$, and $4^{\circ}$ $\mathrm{C}$ until finished. The resulting cDNA was stored at $-20^{\circ}$ $\mathrm{C}$ for subsequent polymerase chain reaction (PCR) amplification. Expression analysis was performed using quantitative real-time PCR with SYBR Green I (TakaRa, Japan) on an ABI 7500 real time PCR system (Applied Biosystem Inc., USA). Primers for TLR7 and TLR8 were designed using Primer Express program (ABI) and their specificity was examined with BLAST queries in the National Center for Biotechnology Information (NCBI) database. The following 5' to 3' oligoucleotides were used: For TLR7, AATGTCACAGCCGTCCCTAC (sense) and GCGCATCAAAAGCATTTACA (antisense); for TLR8, TGTGATGGTGGTGCTTCAAT (sense) and ATGCCCCAGAGGCTATTTCT (antisense). Thermal cycler parameters included 40 cycles at $95^{\circ} \mathrm{C}(5$ s) and $60^{\circ} \mathrm{C}(34 \mathrm{~s})$. The dissolution curve conditions were $95^{\circ} \mathrm{C}$ for $15 \mathrm{~s}, 60^{\circ} \mathrm{C}$ for $1 \mathrm{~min}$, and $95^{\circ} \mathrm{C}$ for $15 \mathrm{~s}$. All gene-specific mRNA expression values were normalized against the housekeeping gene, glyceraldehyde 3phosphate dehydrogenase (GAPDH). After amplification, melting curves were generated automatically by the ABI 7500 ; only those showing a single high production peak were considered to be valid amplifications. PCR amplification of the RNA sample alone (without reverse transcriptase treatment) was performed as a control; no products of the TLR7/8 gene were detected indicating that there was no relevant DNA contamination of the RNA sample.

\section{Statistical analysis}

Data are depicted as means \pm SEM or given as median values (IQRs). All statistical tests used for data analysis were performed using the SPSS Version 11.5 software package (SPSS, Inc. Chicago). Differences among the groups were compared using the Fisher's least significant difference test (LSD) and correlation was determined using the Pearson test for unpaired and normal data. Differences between groups were compared using the Mann-Whitney $U$ test, and correlation was analyzed using the Spearman rank test for unpaired and non-normal data. Wilcoxon signed rank tests were used for comparisons of non-normal paired data. Probability values were two-sided and considered to be significant when $p<0.05$.

\section{Results}

Expression of toll-like receptor 7/8 in peripheral blood monocytes is associated with AIDS progression

To better understand the effect of HIV infection on the expression of TLR7/8 in monocytes, total RNA was 
extracted from purified monocytes of HIV-infected subjects and uninfected subjects; TLR7 and TLR8 mRNA was then measured using real-time PCR. Figure 1A shows that TLR7 mRNA levels in monocytes were significantly increased in SPs versus uninfected subjects, chronic HIV infection subjects, and AIDS subjects ( $p=$ $0.0483, p=0.0473$, and $p<0.0001$ respectively), but were significantly decreased in AIDS subjects in comparison to uninfected subjects $(p=0.0252)$ and chronic HIV infection subjects $(p=0.0108)$. The expression of TLR8 was significantly decreased in subjects with AIDS compared with both uninfected subjects and SPs ( $p=$ $0.0414, p=0.0169)$. No difference in TLR8 was seen among SPs, chronic HIV infection subjects, and uninfected controls. In addition, we found that TLR7 and
TLR8 mRNA levels are significantly correlated with CD $4^{+}$cell counts (Figure $\left.1 \mathrm{~B}\right)(\mathrm{TLR} 7, \mathrm{r}=0.614, p<$ 0.0001 ; TLR8, $\mathrm{r}=0.419, p=0.0014)$. Taken together, expression of TLR7 and TLR8 in monocytes was correlated with AIDS disease progression and appeared to decrease as with advancing severity of disease from SPs to AIDS.

\section{$\mathrm{R}-848$ influence on toll-like receptor $7 / 8$ expression in monocytes in vitro}

To determine if innate immune signals may play a role in the decrease of TLR expression in monocytes in HIV infection, we evaluated the effect of the TLR7/8 ligand, R-848 (resiquimod) [19], on TLR7 and TLR8 expression in cultured monocytes. R-848 functions as an analogue
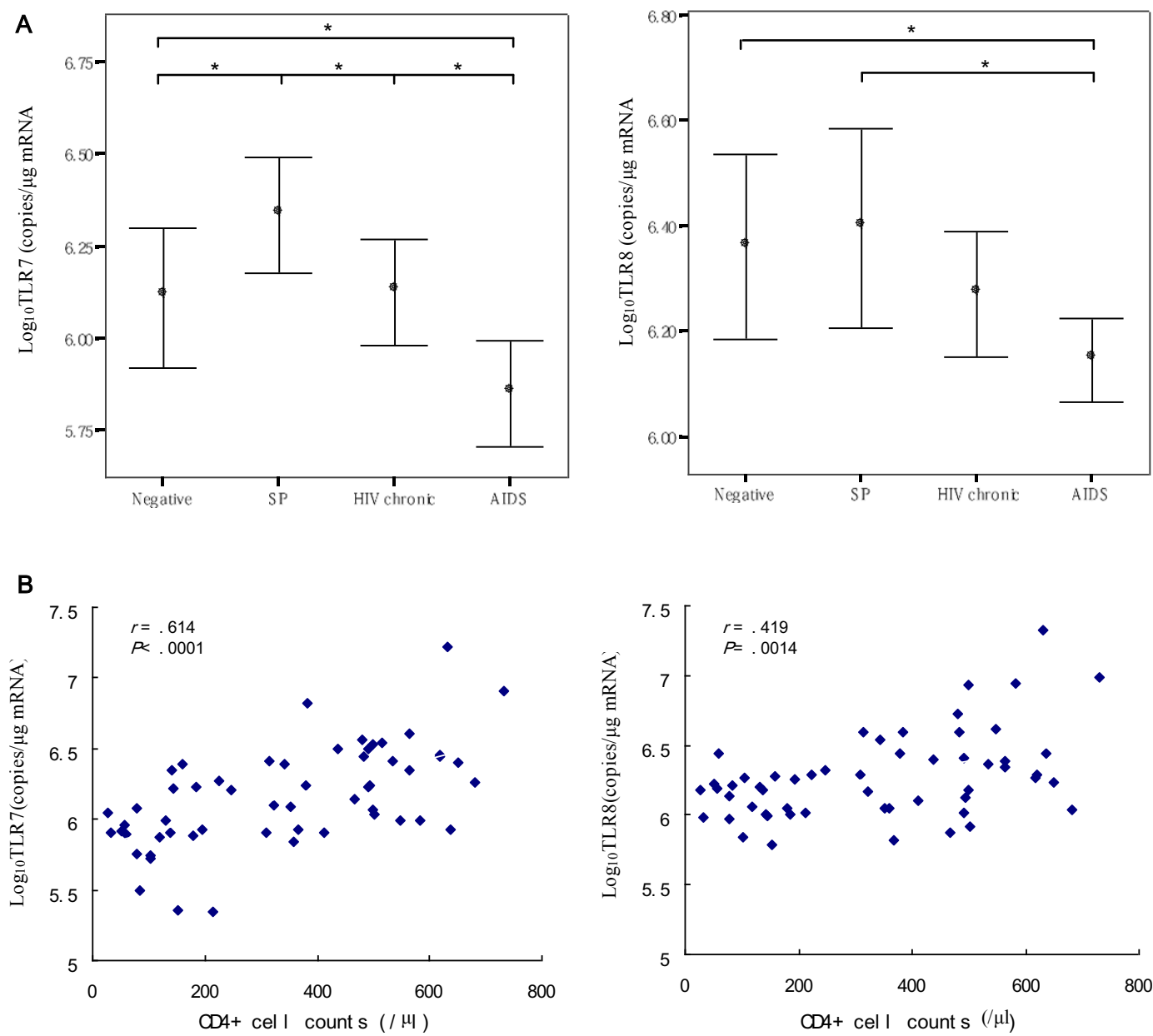

Figure 1 Expression of Toll-like receptor $7 / 8$ in peripheral blood monocytes is associated with AIDS progression and correlates positively with $\mathrm{CD}^{+}$cell counts. (A) Expression of TLR7 was significantly increased in slow progressors (SPs) versus uninfected subjects, chronic HIV infected subjects, and subjects with AIDS. TLR7 expression was also significantly increased in subjects with chronic HIV infection versus AIDS. TLR7 in subjects with AIDS was significantly decreased compared to uninfected subjects. The expression of TLR8 was significantly decreased in subjects with AIDS compared with both uninfected subjects and SPs, ${ }^{*} p<0.05$. Comparisons were made with one-way ANOVA LSD tests. All data are expressed as the mean \pm SEM values from experiments performed in triplicate. (B) The expression of TLR7 and TLR8 was significantly correlated with $\mathrm{CD}^{+}$cell counts. Data was analyzed using the Spearman rank correlation with a level of significance of $\alpha=0.05$ 
of retroviral ssRNA to initiate signaling through both TLR7 and TLR8. Monocytes from five HIV-infected and three uninfected subjects were tested ex vivo (Table 2). Stimulation with R-848 significantly decreased expression of TLR7 in monocytes derived from both HIVinfected and uninfected subjects $(p=0.025)$. Treatment with $\mathrm{R}-848$ did not alter TLR8 expression $(p=0.944)$ (Figure 2). Expression of TLR7/8 in monocytes from either HIV-infected or uninfected subjects appears the same (data not shown).

\section{Response of TLR7 and TLR8 in monocytes contributes to HIV infection}

To assess whether alterations in TLR7 and TLR8 expression associated with HIV infection resulted in altered TLR signaling, we compared the induction of TNF- $\alpha$ and IL- 12 p40 by R-848 in monocytes from ten chronic HIV infection subjects (Table 2) and nine uninfected subjects. Stimulation of monocytes with R-848 resulted in the significant production of TNF- $\alpha$ and IL12 p40 compared with no production in media alone (Figure 3A). Significantly lower TNF- $\alpha$ production was seen in HIV-infected subjects compared with uninfected subjects. The production of IL-12p40 trended towards elevated expression but this increase was not significant. Additionally, we analyzed the relationship between TLR7 or TLR8 expression and production of these two cytokines but found no correlation (data not shown). Lack of correlation suggests that increased TLR7/8 expression does not result in increased cytokine secretion. Therefore, we propose that increased TLR7/8 expression may enhance the cell's ability to recognize ssRNA of virions. Further studies are warranted to confirm our observations.
Interestingly, we found that the production of TNF- $\alpha$ and IL-12p40 secreted by monocytes via TLR7/8 was significantly correlated with $\mathrm{CD}^{+}$cell counts in HIVinfected individuals (Figure $3 \mathrm{~B}$ ). This data indicates that $\mathrm{CD}^{+}{ }^{+}$cell counts could reflect TLR7/8-mediated monocyte secretion function. So we observed the level of TNF- $\alpha$ and IL-12p40 secretion of monocytes from subjects of four groups in order to learn monocytes responsiveness during the HIV infection progression. We have found that TNF- $\alpha$ and IL-12p40 secretions of triggered monocytes were significant difference at each HIV infection disease stage (Figure 3D, $* p<0.05$ ).

\section{R-848 inhibits HIV replication in monocytes through the TLR7/8 pathway}

The correlation of monocyte cytokine secretion capacity with an individual's HIV disease progression status may imply a protective role for the TLR7/8 pathway. We investigated whether the TLR7/8 pathway could contribute to HIV replication in monocytes, since studies have shown that monocytes are considered underestimated HIV-1 viral reservoirs [20]. We first isolated monocytes from nine chronic HIV-infected subjects (Table 2) and cultured them for $48 \mathrm{~h}$ to assess the ability of HIV to replicate in monocytes. HIV RNA loads in the culture supernatants were found to be low in six samples and were not detected in the other three. We found that culture supernatants of monocytes from subjects with $\mathrm{CD}^{+}$cell counts $<400$ cells/ $\mu$ had significantly higher HIV RNA loads than those with $>400$ cells $/ \mu$ l (Figure 4 ).

R-848 has been found to be a TLR7/8 agonist with demonstrated antiviral and anti-tumor activity [21,22]. Oral administration of $\mathrm{R}-848$ has previously been

Table 2 Details of HIV infected subjects from whom monocytes were isolated and cultured ex vivo

\begin{tabular}{|c|c|c|c|c|c|c|c|}
\hline Subject No. $^{a}$ & Sex (age) ${ }^{c}$ & CD4 Count (cells/ $\mu \mathrm{l})$ & CD8 Count (cells/ $\mu \mathrm{l})$ & Plasma Viral Load (copies/ml) & $\mathrm{HCV}^{\mathrm{b}}$ & $\mathrm{HBV}^{\mathbf{b}}$ & HIV Subtype \\
\hline 1 & $M(42)$ & 332 & 1326 & 18800 & $P$ & $P$ & CRF07-BC \\
\hline 2 & $F(38)$ & 412 & 1373 & 92300 & $\mathrm{~N}$ & $\mathrm{~N}$ & CRF01-AE \\
\hline 3 & $M(45)$ & 368 & 463 & 71000 & $P$ & $\mathrm{~N}$ & $B$ \\
\hline 4 & $M(22)$ & 484 & 1333 & 60100 & $\mathrm{~N}$ & $\mathrm{~N}$ & B \\
\hline 5 & $M(40)$ & 364 & 842 & 3200 & $\mathrm{~N}$ & $\mathrm{~N}$ & CRF01-AE \\
\hline 6 & $M(46)$ & 265 & 421 & 140000 & $\mathrm{~N}$ & $\mathrm{~N}$ & CRF01-AE \\
\hline 7 & $M(33)$ & 328 & 485 & 63000 & $\mathrm{~N}$ & $\mathrm{~N}$ & CRF01-AE \\
\hline 8 & $F(45)$ & 480 & 737 & $<10$ & $P$ & $\mathrm{~N}$ & $\mathrm{~B}^{\prime}$ \\
\hline 9 & $F(45)$ & 359 & 1064 & 3600 & $\mathrm{~N}$ & $P$ & $\mathrm{~B}^{\prime}$ \\
\hline 10 & $M(32)$ & 276 & 869 & 830000 & $P$ & $P$ & $B^{\prime}$ \\
\hline
\end{tabular}

\footnotetext{
${ }^{a}$ Monocytes from subjects no.2,3,4,5,7 were used to analyze R-848 influence on expression of TLR7/8; Monocytes from subjects no.1-10 were used to examine TLR7/8 signaling capacity; monocytes from subjects no.1-9 were used to examine HIV replication suppression mediated by TLR7/8. No subjects received HAART therapy

${ }^{\mathrm{b}}$ Minor or no biochemical signs of ongoing liver inflammation (alanine aminotransferase level < 70); P, Positive; N, Negative

${ }^{c} M$, male; $F$, female; age in years
} 


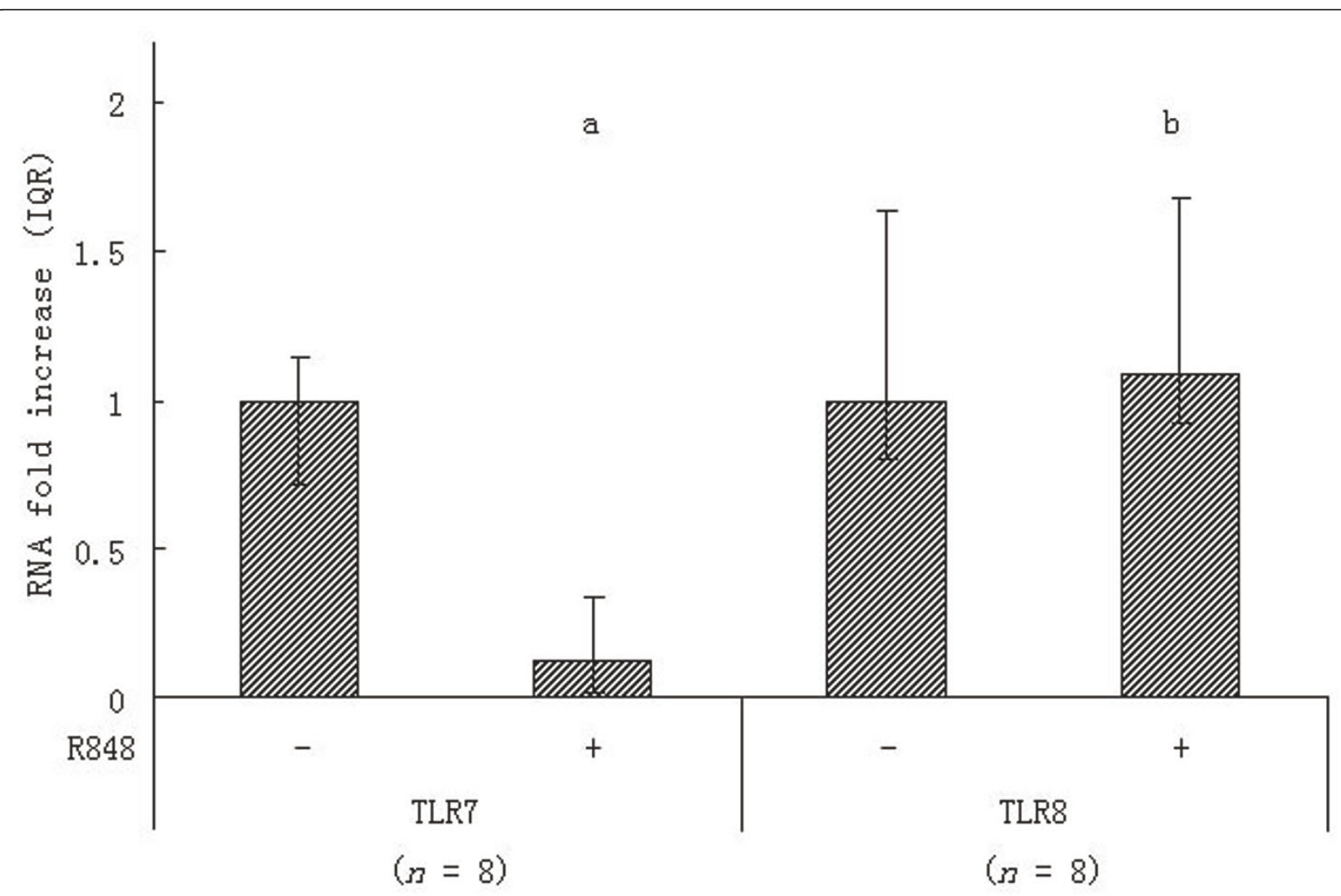

Figure $\mathbf{2}$ R-848 alters Toll-like receptor expression in vitro. Freshly isolated monocytes from uninfected $(n=3)$ and HIV-infected $(n=5)$ subjects were cultured in the presence of R-848 or media alone for $24 \mathrm{~h}$. TLR7/8 mRNA then quantified using real-time PCR. R-848 stimulation significantly decreased expression of TLR7 in monocytes ( $\left.{ }^{a} p=0.025\right)$ but did not alter TLR8 expression $\left({ }^{b} p=0.944\right)$. Data was analyzed using the Wilcoxon signed ranks test. Bars indicate the interquartile range (IQR).

tested against chronic HCV infection [23]. Importantly, $\mathrm{R}-848$ has been shown to block HIV replication in acutely infected PBMCs by triggering TLR7/8 [24]. To further understand whether the TLR7/8 triggering could impact HIV replication in monocytes specifically, we cultured monocytes from subjects with chronic HIV infections with R-848 for $48 \mathrm{~h}$ and monitored supernatant HIV RNA load as an indicator of HIV replication. We found that HIV replication in culture supernatants significantly decreased in five cases, increased in one case, and showed no replication with or without R-848 in the other three cases (Figure 5). Cytokine levels and TLR mRNA were quantified in the culture supernatant exhibiting increased HIV replication; TNF measured 1399 pg/ml, IL-12 measured 464 $\mathrm{pg} / \mathrm{ml}$, TLR 7 mRNA was 5.87 copies/ $\mu \mathrm{g}$, and TLR8 mRNA was 6.13 copies/ $\mu$ g (Subject \#1 in Table 2). Subject \#1's TLR functional status showed no distinguishing feature but his culture was infected with HIV subtype (CRF07-BC). Whether this particular HIV subtype may be able to escape TLR 7/8's effect on replication merits further investigation.

\section{Discussion}

This study, to our knowledge, represents the first analysis of the expression of TLR7/8 on monocytes during HIV disease progression and the role of TLR7/8 triggering in monocytes on viral replication.

Monocytes are vital members of the innate immune system as they are precursors to professional antigen presenting cells (APCs). However, monocytes have been implicated as a viral reservoir during HIV infection based on the detection and recovery of replication-competent virus from circulating monocytes isolated from HIV-positive individuals $[20,25,26]$. In our study, we isolated blood monocytes from nine HIV-infected subjects and cultured the samples in vitro. Monocytes from six of nine HIV-infected subjects exhibited HIV replication, which indicates that peripheral blood monocytes of $\mathrm{HIV}$-infected patients contain replication-competent HIV particles.

Recently, Almodovar et al. [27] reported that peripheral blood monocytes do not seem to be latent sources of HIV in the presence of suppressive HAART (highly active retroviral therapy); however, in the absence of 

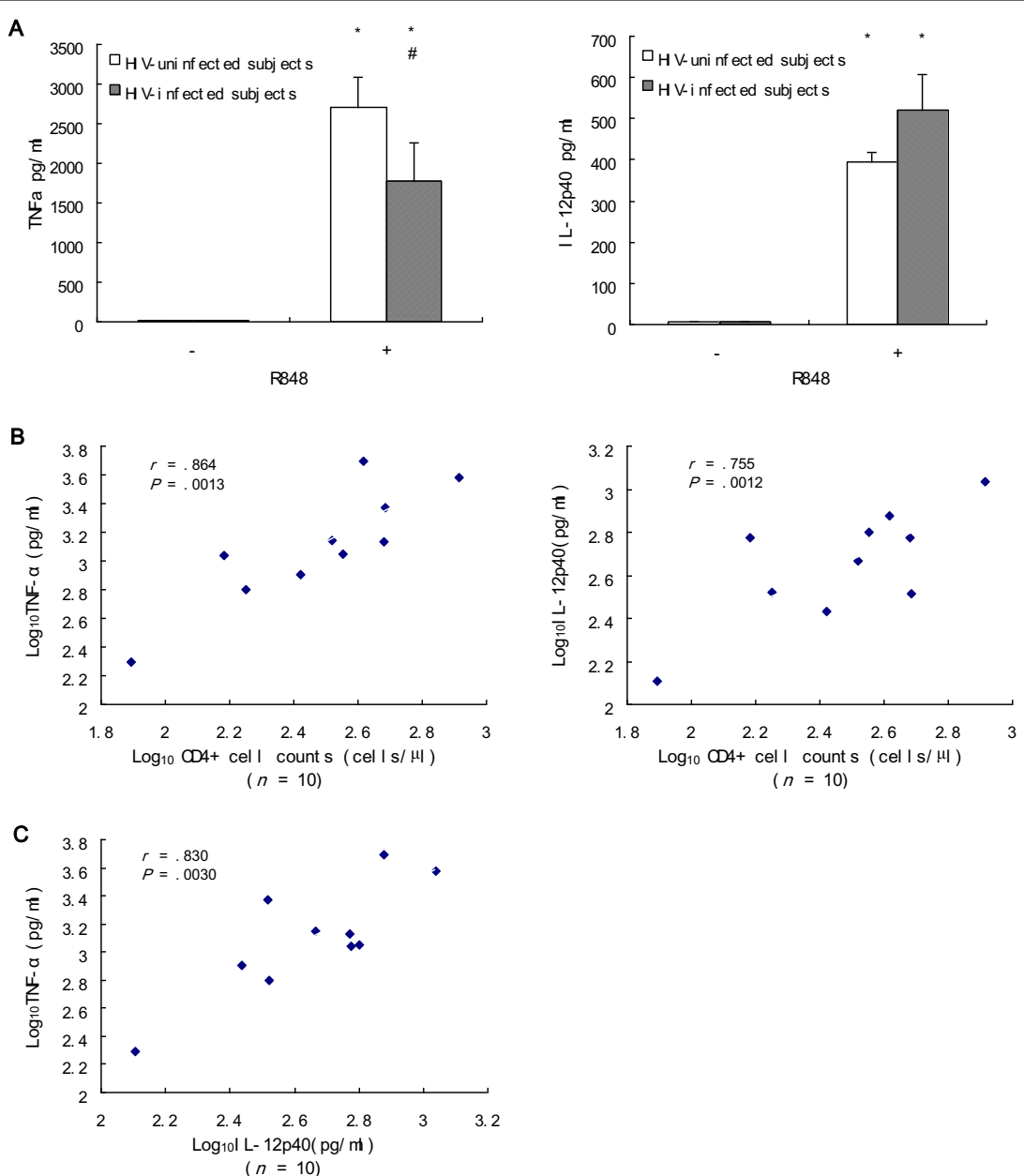

D
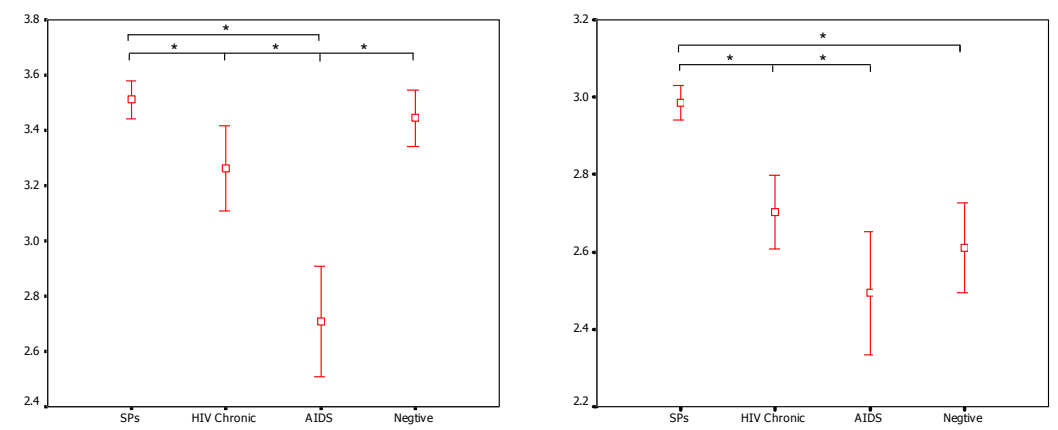

Figure 3 Proinflammatory cytokine secretion mediated by TLR7/8 in monocytes varied based on HIV-infection status and correlated positively with $\mathrm{CD}^{+}$cell counts of peripheral blood in HIV-infected subjects. Ex vivo monocytes from uninfected $(n=10)$ and HIV-infected $(n=10)$ subjects were cultured in the presence of TLR $7 / 8$ ligand R-848 or media alone for $24 \mathrm{~h}$. Culture supernatants were assessed for cytokine levels using an ELISA assay. (A) R-848 stimulation produced significantly greater TNF- $\alpha$ production in monocytes of both HIV-infected and uninfected subjects compared with unstimulated samples $(p<0.0001)$; stimulated uninfected subjects produced more TNF- $\alpha$ than stimulated HIVinfected subjects $(p=0.0412)$. R-848 also induced significantly greater IL-12p40 production in monocytes of both HIV-infected $(p<0.0001)$ and uninfected subjects compared with unstimulated monocytes $(p<0.0001)$. No statistically significant increase in IL-12p40 was observed in HIVinfected versus uninfected subjects $(P=0.198)$. TNF- $\alpha$ levels were analyzed using the Mann-Whitney $U$ two-tailed test. Independent $t$ test were used to analyze IL-12p40 levels. The significant differences are represented as $p$ value ${ }^{*} p<0.0001$ compared with unstimulated by R-848, \#p= 0.0412 compared with uninfected subjects). All data are expressed as the mean \pm SEM values from experiments performed in triplicate. (B) Levels of TNF- $\alpha$ and IL-12p40 secreted by monocytes via TLR7/8 were significantly correlated with CD4 ${ }^{+}$cell counts in the ten HIV-infected individuals. (C) TNF- $\alpha$ exhibited a significant positive correlation with IL-12p40 in HIV-infected individuals. Data was analyzed using a Pearson correlation. Experiments were repeated at least 2 times with similar results. (D) The level of TNF- $\alpha$ and IL-12p40 secretions of triggered monocytes derived from 31 subjects belonging to the four categories (7 subjects of SPs, 10 of HIV Chronic, 7 of AIDS and 7 of Negative) were described $\left({ }^{*} p<0.05\right)$. 


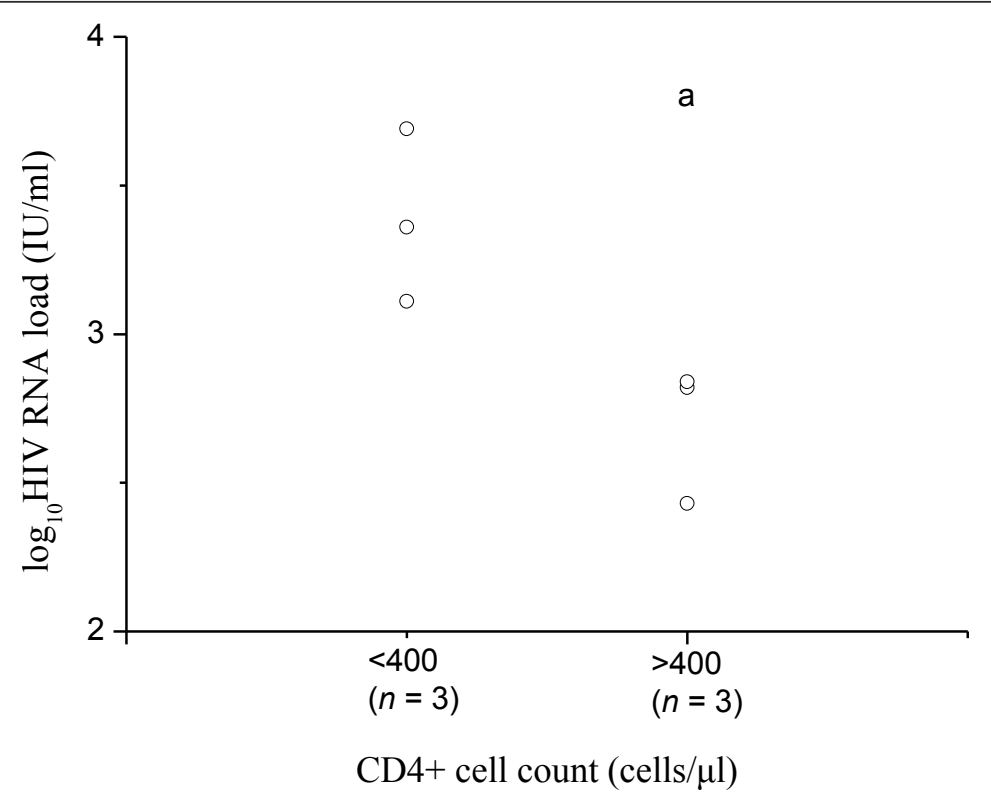

Figure 4 HIV RNA levels in monocyte culture supernatants are associated with peripheral blood CD4 ${ }^{+}$cell counts. Monocytes isolated from HIV-infected subjects $(n=9)$ were cultured in vitro. Supernatants in six subjects produced low levels of productive viral particles. HIVinfected subjects were divided into two groups by $\mathrm{CD}^{+}$cell count around a median of 400 cells/ $\mu$ l. HIV RNA levels (viral load, logarithmically scaled) of each group are shown. The group with $<400 \mathrm{CD} 4^{+}$cells/ $/ \mu$ had higher HIV replication levels than the group of $>400 \mathrm{CD} 4^{+}$cells/ $\mu \mathrm{l}$ $\left({ }^{a} p=0.0323\right)$. Data was analyzed using an independent $t$ test.

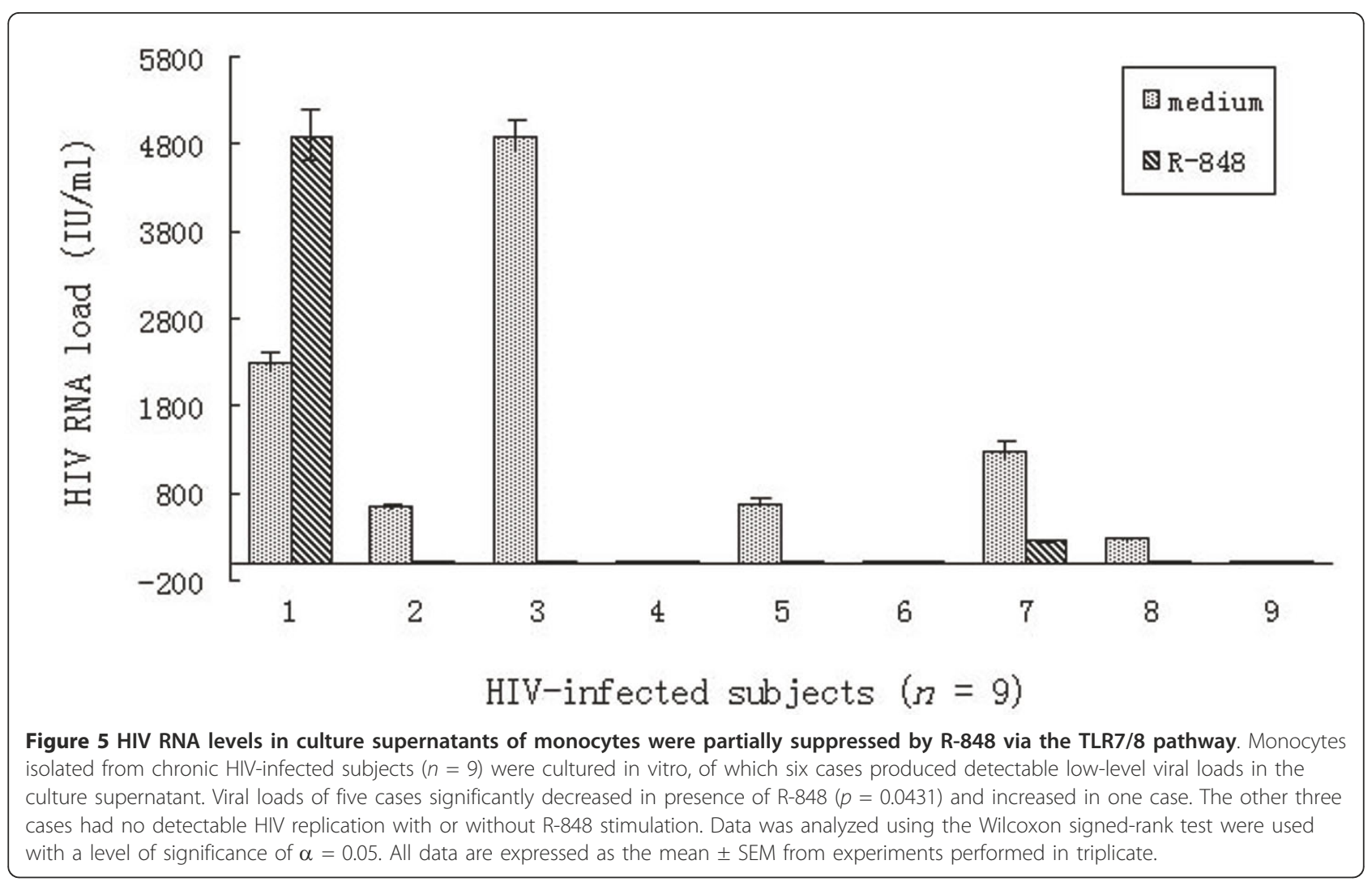


suppressive HAART, monocytes may become infected with HIV. In our study, although all nine patients were HAART-naïve, three did not show HIV replication which suggests that inhibition of HIV replication may be host-mediated $[28,29]$. However, we cannot rule out that this result could be explained by our 48 -h culture protocol, which may have been insufficient to allow detectable viral replication in these three samples.

Several studies have demonstrated that, even in individuals with viral loads suppressed below detection for prolonged periods of time, HIV-1 still continues to replicate at very low levels in monocytes and that infected monocytes can transmit HIV-1 to other susceptible cells $[20,26,30]$. Suppression or elimination of HIV in infected subjects' monocytes would be an important method of preventing rebound infection. In our study, we provide evidence that TLR7/8 triggering by the TLR7/8 agonist, R-848, can suppress HIV replication in monocytes. Moreover, a TLR7/8-initiated pathway can induce a protective adaptive immune response that leads to suppression of the pathogen [31-33], which indicates that there are multiple roles for TLR7/8 in an antiviral response.

The mechanism of HIV-1 latency in monocytes is not fully understood. Given that the TLR7/8 receptors on monocytes can recognize viral ssRNA and thus mediate an antiviral immune response, we considered whether the replication of HIV could be inhibited by triggering the TLR7/8 signaling pathway. Our data demonstrate that $\mathrm{R}-848$ can inhibit HIV replication in monocytes cultured from HIV-infected subjects, which suggests that this inhibition is related to the TLR7/8 signaling pathway and is dependent on monocytes themselves and not on input from other cell types.

We also investigated whether inhibition of replication could be related to the role of proinflammatory factors secreted by monocytes after agonist stimulation. Several studies have reported that TNF- $\alpha$ may induce HIV replication in vitro $[34,35]$. Other studies have noted a general increased in circulating TNF- $\alpha$ during HIV infection [36,37] We compared HIV-infected and healthy subjects by examining TNF- $\alpha$ and IL-12p40 in monocyte culture supernatants. We observed reduced TNF- $\alpha$ secretion by monocytes from HIV-infected patients following stimulation with R-848. In this respect, our results differ from previous results that show increased monocyte TNF- $\alpha$ secretion due to stimulation with gp120 and HIV virions [38-40]. As R-848 has a molecular structure similar to ssRNA, it is ideal for studying TLR7/8 signaling. However, R-848 cannot substitute for treatment with gp120 or complete HIV virions. Other components of the HIV virion may provide a significant source of stimulus for innate immune activation [41].
Among the six patients with positive HIV replication, we found that patients with lower $\mathrm{CD} 4^{+}$cell counts had higher HIV replication levels, which supports the findings of Innocenti et al. [42]. The higher HIV replication levels indicated that the monocytes contained high levels of HIV DNA as compared to monocytes from subjects with high $\mathrm{CD}^{+}$cell counts (which is an established indicator of host immune status). Thus, we hypothesized that TLR7/8 expression may vary HIV infection stage.

Indeed, we found that TLR7 and TLR8 expression levels in monocytes declined as a function of the severity of HIV infection (i.e. slow progression to chronic HIV infection to AIDS). TLR7 expression was decreased significantly at each subsequent stage of HIV infection, while TLR8 expression decreased significantly from baseline levels only at the AIDS stage. Different levels of TLR7/8 expression in different stages of HIV infection suggest that their role in monocyte function also varies according to HIV infection stage. To test this difference further, we used the TLR7/8 ligand R-848 [19] to activate the TLR7/8 signaling pathway [43] in vitro. Our findings show that TNF- $\alpha$ and IL-12p40 secretions were decreased significantly at each subsequent HIV infection stage, which indicated that the decreased TLR7 expression of monocytes should be linked to a lower response to R-848. Meanwhile, our findings also show that TLR7 expression levels are decreased significantly after monocytes are stimulated by $\mathrm{R}-848$ in vitro, which corresponds to the observed pattern of TLR7 expression levels in monocytes across disease progression stages.

This data suggests that TLR7 is more responsive and hypersensitized to its ligands, while TLR8 expression in monocytes in vitro was stable after stimulation with $\mathrm{R}$ 848, which corresponds to the conserved in vivo TLR8 expression in monocytes of subjects from the SPs and HIV chronic stages. Hence this study reveals differences in TLR7 and TLR8 expression in monocytes from HIVinfected subjects both in vivo and after in vitro stimulation; however, further studies are needed to elucidate a mechanistic explanation of altered TLR expression in HIV-infected monocytes.

TLR 7/8 may recognize HIV ssRNA. Binding of the appropriate ligands results in the recruitment of the adaptor protein Myeloid Differentiation Factor 88 (MyD88)followed by various IL-1 receptor-associated kinase (IRAK) family members. TNF receptor-associated factor 6 (TRAF6) is also recruited and finally the NF- $\kappa$ B and mitogen-activated protein kinases (MAPKs) are activated. These events result in the induction of inflammatory cytokines and chemokines [44]. Thus, TLR 7 binding to its ligand could result in the production of cytokines; decreased TLR 7 expression would theoretically lead to a drop in cytokine secretion. However, our study found no correlation between TLR expression and 
TNF or IL-12 secretion (data not shown). We speculate that the expression level of TLR 7 may influence the frequency with which ligands are recognized; the higher the level of TLR expression, the greater chance that a ligand such as ssHIV RNA will be detected.

Our study demonstrates that TLR 7/8 activation elicits an antiviral response in primary monocytes with increased TLR 7 expression at the initial disease (SP stage); thus, we can speculate that at the time of initial HIV-infection, HIV ssRNA may be recognized by TLR 7 and activate signaling pathways resulting in MyD88 activation and subsequent production of proinflammatory cytokines such as IFNs which could increase TLR 7/8 expression [45]. Persistent immune activation in HIV is thought to contribute to pathogenesis by progressively disturbing cytokine expression, functional organization of the immune system [46], and decreasing TLR expression (AIDS stage). Further studies are needed to examine this possibility. Interestingly, our observation of decreased TLR7 and TLR8 mRNA expression in monocytes differs from the increase in TLR7 and TLR8 mRNA expression as Lester et al. reported [47] in PBMCs, which suggests that monocytes experience a unique change in TLR7/8 expression distinct from other PBMCs.

Our study is preliminary and since it is performed in restricted conditions its extrapolation to clinical applications is challenging. It has several limitations. First, the number of cases is limited and this should be taken into consideration when interpreting the results. Nevertheless, to our knowledge, no other study has reported that R-848 inhibited HIV replication specifically in monocytes nor have other studies documented the association between TLR7/8 expression in monocytes and HIV disease progression. Second, TLR7/8 expression was only measured at the mRNA level; analysis of protein levels will increase our understanding of the phenomenon. However, Song et al. [10] have confirmed that enhanced expression of TLR7 mRNA in CD8 ${ }^{+} \mathrm{T}$ cells corresponds to increased TLR7 protein expression. Finally, we have not yet undertaken sophisticated mechanistic studies of the variations in TLR7/8 signaling pathway which may occur during progressive stages of HIV infection.

\section{Conclusions}

Our study reveals a relationship between TLR7/8 mRNA expression levels in monocytes and HIV disease progression. Furthermore, our data indicate that HIV replication can be suppressed via TLR7/8 ligation in vitro. Further analysis of the TLR7 and TLR8 pathway may contribute to the understanding of the immunopathogenesis of HIV infection and may ultimately offer novel targets for immunomodulatory therapy.

\section{Acknowledgements}

We thank Xiao-Ning Xu (University of Oxford) for contributions to the manuscript and thank the experts at BioMed Proofreading for the editing We are grateful to dedicated clinic and laboratory staff. This work was supported by mega-projects of national science research for the 12th FiveYear Plan(2012ZX10001-006), the National Clinical Key Project of Ministry of Health, Liaoning Provincial Medical Key Project (2010-696), and the National Natural Science Foundation of China(30972760)

\section{Author details}

1Key Laboratory of AIDS Immunology of Ministry of Health, Department of Laboratory Medicine, No.1 Hospital of China Medical University, No.155 Nanjing North Street, Heping District, Shenyang 110001, China. ${ }^{2}$ Center for Disease Control and Prevention, Jiamusi, Heilongjiang 154007, China.

\section{Authors' contributions}

HS and WQG conducted the experiments. HN, HLC, YP and MJB carried out all the test. MJB, QHH and MZ participated in the statistical analysis of the study. HS and ZNZ provided a critical review of the manuscript. HS designed the study and supervised the laboratory procedures and the data analysis. HN analyzed and interpreted the results and wrote the manuscript. All authors contributed to writing the manuscript and approved its final version.

\section{Competing interests}

The authors declare that they have no competing interests.

Received: 14 August 2011 Accepted: 14 January 2012

Published: 14 January 2012

\section{References}

1. Levy JA: The importance of the innate immune system in controlling HIV infection and disease. Trends in immunology 2001, 22:312-316.

2. Lehner T: Innate and adaptive mucosal immunity in protection against HIV infection. Vaccine 2003, 21(Suppl 2):S68-S76.

3. Siegal FP, Spear GT: Innate immunity and HIV. AIDS (London, England) 2001, Suppl 5(5):127-13.

4. Takeda K, Kaisho T, Akira S: Toll-like receptors. Annu Rev Immunol 2003, 21:335-376.

5. Barton GM: Viral recognition by Toll-like receptors. Semin Immunol 2007, 19:33-40.

6. Pasare C, Medzhitov R: Toll-like receptors: linking innate and adaptive immunity. Adv Exp Med Biol 2005, 560:11-18.

7. Kumar H, Kawai T, Akira S: Toll-like receptors and innate immunity. Biochem Biophys Res Commun 2009, 388:621-625.

8. Akira S, Uematsu S, Takeuchi O: Pathogen recognition and innate immunity. Cell 2006, 124:783-801.

9. Alter G, Suscovich TJ, Teigen N, Meier A, Streeck H, Brander C, Altfeld M: Single-stranded RNA derived from HIV-1 serves as a potent activator of NK cells. J Immunol 2007, 178:7658-7666.

10. Song $Y$, Zhuang $Y$, Zhai S, Huang D, Zhang $Y$, Kang W, Li X, Liu Q, Yu Q Sun Y: Increased expression of TLR7 in CD8(+) T cells leads to TLR7mediated activation and accessory cell-dependent IFN-gamma production in HIV type 1 infection. AIDS research and human retroviruses 2009, 25:1287-1295.

11. Oh DY, Baumann K, Hamouda O, Eckert JK, Neumann K, Kucherer C, Bartmeyer B, Poggensee G, Oh N, Pruss A, et al: A frequent functional tolllike receptor 7 polymorphism is associated with accelerated HIV-1 disease progression. AIDS (London, England) 2009, 23:297-307.

12. Diebold SS, Kaisho T, Hemmi H, Akira S, Reis e Sousa C: Innate antiviral responses by means of TLR7-mediated recognition of single-stranded RNA. Science (New York, NY) 2004, 303:1529-1531.

13. Heil F, Hemmi H, Hochrein $H$, Ampenberger F, Kirschning C, Akira S, Lipford G, Wagner H, Bauer S: Species-specific recognition of singlestranded RNA via toll-like receptor 7 and 8. Science (New York, NY) 2004, 303:1526-1529.

14. Hiscott J, Kwon H, Genin P: Hostile takeovers: viral appropriation of the NF-kappaB pathway. J Clin Invest 2001, 107:143-151.

15. Bekeredjian-Ding I, Roth SI, Gilles S, Giese T, Ablasser A, Hornung V, Endres S, Hartmann G: T cell-independent, TLR-induced IL-12p70 production in primary human monocytes. I Immunol 2006, 176:7438-7446. 
16. Bonizzi G, Karin M: The two NF-kappaB activation pathways and their role in innate and adaptive immunity. Trends Immunol 2004, 25:280-288.

17. Hartmann G, Krieg AM: CpG DNA and LPS induce distinct patterns of activation in human monocytes. Gene Therapy 1999, 6:893-903.

18. Ellery PJ, Tippett E, Chiu YL, Paukovics G, Cameron PU, Solomon A, Lewin SR, Gorry PR, Jaworowski A, Greene WC, et al: The CD16+ monocyte subset is more permissive to infection and preferentially harbors HIV-1 in vivo. J Immunol 2007, 178:6581-6589.

19. Jurk M, Heil F, Vollmer J, Schetter C, Krieg AM, Wagner H, Lipford G, Bauer S: Human TLR7 or TLR8 independently confer responsiveness to the antiviral compound R-848. Nat Immunol 2002, 3:499.

20. Zhu T, Muthui D, Holte S, Nickle D, Feng F, Brodie S, Hwangbo Y, Mullins JI, Corey $\mathrm{L}$ : Evidence for human immunodeficiency virus type 1 replication in vivo in CD14(+) monocytes and its potential role as a source of virus in patients on highly active antiretroviral therapy. J Virol 2002, 76:707-716.

21. Perry CM, Lamb HM: Topical imiquimod: a review of its use in genital warts. Drugs 1999, 58:375-390.

22. Gibson SJ, Imbertson LM, Wagner TL, Testerman $T L$, Reiter MJ, Miller RL, Tomai MA: Cellular requirements for cytokine production in response to the immunomodulators imiquimod and S-27609. J Interferon Cytokine Res 1995, 15:537-545.

23. Pockros PJ, Guyader D, Patton H, Tong MJ, Wright T, McHutchison JG, Meng TC: Oral resiquimod in chronic HCV infection: safety and efficacy in 2 placebo-controlled, double-blind phase lla studies. J Hepatol 2007, 47:174-182.

24. Schlaepfer $E$, Audige A, Joller $H$, Speck RF: TLR7/8 triggering exerts opposing effects in acute versus latent HIV infection. J Immunol 2006 176:2888-2895.

25. Mikovits JA, Lohrey NC, Schulof R, Courtless J, Ruscetti FW: Activation of infectious virus from latent human immunodeficiency virus infection of monocytes in vivo. J Clin Invest 1992, 90:1486-1491.

26. Sonza S, Mutimer HP, Oelrichs R, Jardine D, Harvey K, Dunne A, Purcell DF, Birch C, Crowe SM: Monocytes harbour replication-competent, non-latent HIV-1 in patients on highly active antiretroviral therapy. AIDS (London England) 2001, 15:17-22.

27. Almodovar S, Del CCM, Maldonado IM, Villafane R, Abreu S, Melendez I, Dominguez C, Cuevas W, Collins TM, Lorenzo E: HIV-1 infection of monocytes is directly related to the success of HAART. Virology 2007, 369:35-46.

28. Naif HM, Li S, Alali M, Chang J, Mayne C, Sullivan J, Cunningham AL: Definition of the stage of host cell genetic restriction of replication of human immunodeficiency virus type 1 in monocytes and monocytederived macrophages by using twins. J Virol 1999, 73:4866-4881.

29. Triques $K$, Stevenson M: Characterization of restrictions to human immunodeficiency virus type 1 infection of monocytes. J Virol 2004, 78:5523-5527.

30. Lambotte O, Taoufik Y, de Goer MG, Wallon C, Goujard C, Delfraissy JF: Detection of infectious HIV in circulating monocytes from patients on prolonged highly active antiretroviral therapy. J Acquired Immune Deficiency Syndromes (1999) 2000, 23:114-119.

31. Koyama S, Ishii KJ, Kumar H, Tanimoto T, Coban C, Uematsu S, Kawai T, Akira S: Differential role of TLR- and RLR-signaling in the immune responses to influenza A virus infection and vaccination. J Immunol 2007 179:4711-4720.

32. Reis e Sousa C: Activation of dendritic cells: translating innate into adaptive immunity. Current Opin Immunol 2004, 16:21-25.

33. Iwasaki A, Medzhitov R: Toll-like receptor control of the adaptive immune responses. Nat Immunol 2004, 5:987-995.

34. Aukrust P, Muller F, Lien E, Nordoy I, Liabakk NB, Kvale D, Espevik T, Froland SS: Tumor necrosis factor (TNF) system levels in human immunodeficiency virus-infected patients during highly active antiretroviral therapy: persistent TNF activation is associated with virologic and immunologic treatment failure. J Infect Dis 1999, 179:74-82

35. Kedzierska K, Crowe SM: Cytokines and HIV-1: interactions and clinical implications. Antivir Chem Chemother 2001, 12:133-150.

36. Khanna KV, Yu XF, Ford DH, Ratner L, Hildreth JK, Markham RB: Differences among HIV-1 variants in their ability to elicit secretion of TNF-alpha. J Immunol 2000, 164:1408-1415.

37. Bergamini A, Faggioli E, Bolacchi F, Gessani S, Cappannoli L, Uccella I, Demin F, Capozzi M, Cicconi R, Placido R, et al: Enhanced production of tumor necrosis factor-alpha and interleukin- 6 due to prolonged response to lipopolysaccharide in human macrophages infected in vitro with human immunodeficiency virus type 1. J Infect Dis 1999, 179:832-842.

38. Rimaniol AC, Boussin FD, Dormont D, Bach JF, Zavala F: Mechanisms of downmodulation and release of tumour necrosis factor receptor induced by human immunodeficiency virus type 1 in human monocytes. Cytokine 1997, 9:9-18.

39. Merrill JE, Koyanagi Y, Chen IS: Interleukin-1 and tumor necrosis factor alpha can be induced from mononuclear phagocytes by human immunodeficiency virus type 1 binding to the CD4 receptor. J Virol 1989, 63:4404-4408.

40. Zembala M, Pryjma J, Plucienniczak A, Szczepanek A, Jasinski M, Ruggiero I, Piselli P, Colizzi V: Interaction of HIV-1 gp120 molecule fragments with human monocytes: different requirements for tumor necrosis factoralpha and IL-6 production. Clin Immunol Immunopathol 1995, 75:131-139.

41. Catalfamo M, Di Mascio M, Hu Z, Srinivasula S, Thaker V, Adelsberger J, Rupert A, Baseler M, Tagaya Y, Roby G, et al: HIV infection-associated immune activation occurs by two distinct pathways that differentially affect CD4 and CD8 T cells. Proc Natl Acad Sci USA 2008, 105:19851-19856.

42. Innocenti P, Ottmann M, Morand P, Leclercq P, Seigneurin JM: HIV-1 in blood monocytes: frequency of detection of proviral DNA using PCR and comparison with the total CD4 count. AIDS Res Human Retroviruses 1992, 8:261-268.

43. Hart OM, Athie-Morales V, O'Connor GM, Gardiner CM: TLR7/8-mediated activation of human NK cells results in accessory cell-dependent IFNgamma production. J Immunol 2005, 175:1636-1642.

44. Akira S, Takeda K: Toll-like receptor signalling. Nat Reviews 2004, 4:499-511.

45. Miettinen M, Sareneva T, Julkunen I, Matikainen S: IFNs activate toll-like receptor gene expression in viral infections. Genes and Immunity 2001, 2:349-355.

46. Grossman Z, Meier-Schellersheim M, Paul WE, Picker LJ: Pathogenesis of HIV infection: what the virus spares is as important as what it destroys. Nat Med 2006, 12:289-295.

47. Lester RT, Yao XD, Ball TB, McKinnon LR, Kaul R, Wachihi C, Jaoko W, Plummer FA, Rosenthal KL: Toll-like receptor expression and responsiveness are increased in viraemic HIV-1 infection. AIDS (London, England) 2008, 22:685-694.

\section{Pre-publication history}

The pre-publication history for this paper can be accessed here: http://www.biomedcentral.com/1471-2334/12/5/prepub

doi:10.1186/1471-2334-12-5

Cite this article as: Nian et al:: R-848 triggers the expression of TLR7/8 and suppresses HIV replication in monocytes. BMC Infectious Diseases 2012 12:5

\section{Submit your next manuscript to BioMed Central and take full advantage of:}

- Convenient online submission

- Thorough peer review

- No space constraints or color figure charges

- Immediate publication on acceptance

- Inclusion in PubMed, CAS, Scopus and Google Scholar

- Research which is freely available for redistribution

Submit your manuscript at www.biomedcentral.com/submit
C Biomed Central 